\title{
Digital citizenship in schools: nine elements all students should know, in Mike Ribble,
}

\author{
3.ed. Arlington, VA, USA: International \\ Society for Technology in Education, 2015.
}

\begin{abstract}
Simão Pedro P. Marinho
Doutor em Educação. Professor Titular da Pontífica Universidade Católica de Minas. Minas Gerais - MG - Brasil sppm@uol.com.br

Flávia Cardoso Carneiro

Doutoranda em Educação pela Pontifícia Universidade Católica de Minas. Professora na área de Gestão do Centro Universitário UNA, Faculdade de Estudos Administrativos de Minas Gerais e do Serviço Nacional de Aprendizagem Comercial.

flaviacar@yahoo.com
\end{abstract}

A cidadania é um dos princípios fundamentais da República no Brasil (BRASIL,1988), conforme o art. $1^{\circ}$ da nossa Constituição. A Lei 9394/96 define e regulariza a organização da educação brasileira com base nos princípios presentes na Constituição. Em seu Art. $2^{\circ}$, a referida lei é explícita: "A educação, dever da família e do Estado, inspirada nos princípios de liberdade e nos ideais de solidariedade humana, tem por finalidade o pleno desenvolvimento do educando, seu preparo para o exercício da cidadania e sua qualificação para o trabalho" (BRASIL, 1996, grifo nosso). Portanto, além de espaço democrático de pleno exercício da cidadania, cabe à escola, mais especialmente na Educação Básica, conforme os Art. 22 e 35 da Lei, formar os alunos para que exerçam a cidadania. Formar na cidadania e para a cidadania é missão da escola. Por outro lado, a ONU, considerando a importância da natureza "transformadora e única da internet” (2011), reconheceu que navegar na rede mundial de computadores é direito humano básico.

Entretanto, é essencial a compreensão de que direitos implicam deveres. Ao contrário do que se constata cotidianamente, as pessoas não podem apenas evocar direitos; elas devem estar atentas aos seus deveres e compromissos para com os demais. Dessa forma, o direito de navegar na internet exige considerar a responsabilidade quando se acessa a grande rede, quando ali se expressa, sob as diversas formas de linguagem. Afinal, 
"estar conectado é uma condição à participação na contemporaneidade, ao exercício pleno da cidadania, ao acesso e expressão ampla e transparente à informação e a meios para a sua produção e compartilhamento e participação social." (ALMEIDA; SILVA, 2014, p.1240) Não é sem motivo que o Marco Civil da Internet (BRASIL, 2015) define direitos e deveres para o uso da internet no país, além de estabelecer diretrizes para atuação da União, estados, DF e municípios em relação ao acesso e uso da rede mundial de computadores.

Exatamente por isso passa a ser importante a temática da cidadania digital, que diz respeito ao uso das Tecnologias Digitais de Informação e Comunicação (TDIC) de forma responsável por parte dos indivíduos. Mesmo que a educação para o pleno exercício da cidadania digital deva ser compromisso da escola e da família, compartilhadamente, tende a haver grande ênfase no trabalho que caberá à escola. Nessa perspectiva, o livro de Ribble, ainda que elaborado no contexto dos EUA, oferece 9 elementos que podem ajudar educadores a entender todas as variáveis que constituem a formação da cidadania digital e prover, como em um guia, uma maneira organizada para a sua abordagem nas escolas. No entanto, como as TDIC não cessam de evoluir, qualquer tentativa de criar-se um manual rapidamente torna-se ultrapassado. As diretrizes para a regulamentaçáo das TDIC não conseguem acompanhar a velocidade da demanda por elas, suas aplicações se multiplicam de forma exponencial enquanto as regras progridem de maneira linear.

Com o objetivo de abordar a questão da formação para a cidadania digital e evitar impasses morais e éticos deixados pelas lacunas do posicionamento legal do Estado, Ribble delineou 9 elementos. Dentre eles, alguns deverão ser mais abordados por provedores de tecnologia, enquanto outros estariam sob o foco da escola, sendo alguns deles de responsabilidade compartilhada com a família.

O primeiro elemento abordado por Ribble é o direito ao acesso, definido como a participação eletrônica irrestrita na sociedade. De fato, o acesso é imprescindível para o exercício da cidadania digital pelos indivíduos. Ribble considera que o foco de governos mundiais deve estar no aperfeiçoamento do acesso à rede, tanto em escolas quanto fora delas. Segundo diretrizes da ONU (UNITED NATIONS, 2011) que estabelecem o acesso à internet como direito humano, as açóes governamentais 
pela educação e formação de crianças e jovens devem promover a expansão do acesso à tecnologia para que ela alcance todos os seus cidadáos.

A segunda consideração gira em torno do comércio digital, compra/ venda de bens e serviços por meios eletrônicos. O comércio legal e legítimo ocorre cada vez em maior grau e frequência. Em 2017 o e-commerce global girou em torno de US\$2,3 trilhóes e as projeçóes giram em torno de US\$4,88 trilhóes até 2021. Entretanto, usuários precisam estar atentos pois atrelado ao crescimento do consumo legal de bens e serviços vem o comércio ilegal ou imoral desses mesmos bens e serviços, de acordo com as leis específicas de cada país.

A comunicação digital, designada troca eletrônica de informações, consiste na habilidade da pessoa comunicar-se com outras pelos meios eletrônicos. A capacidade de operar novos meios de comunicação e interagir digitalmente por intermédio deles determina o grau de inserção do indivíduo na nova realidade. A comunicação digital demanda, portanto, letramento digital adequado, uma preparação para o uso das ferramentas que figuraria, primariamente, como dever da escola e, num segundo momento, da família. No mundo do trabalho, no qual as TDIC também já dominam processos e práticas, há necessidade de letramento digital, de maneira que trabalhadores possam desempenhar seu potencial usando, de maneira eficaz, as novas ferramentas disponíveis. Esse processo demanda habilidades sofisticadas de busca/processamento de informaçóes alcançadas pelo letramento informacional. Crianças, jovens e adultos precisam ser formados para que possam aprender na sociedade digital. Isso consiste em aprender qualquer coisa, a qualquer hora, em qualquer lugar, respeitando os padróes eletrônicos de conduta e procedimentos, a etiqueta digital. Ribble considera essa área como a mais crítica na formação para a cidadania digital, pois se apoia em valores morais e éticos específicos de cada sociedade e indivíduo, dependendo de sua formação e cultura. Assim, a adoção de padrôes universais de conduta e comportamento digital facilitaria a comunicação entre pessoas e empresas de todos os países.

Já a lei digital vem sendo forjada a partir dos problemas causados pela ausência de responsabilidade eletrônica, individual ou coletiva, sobre obras e açóes. Os usuários precisam entender que o roubo ou o dano a qualquer trabalho, identidade ou propriedade de outra pessoa online é crime, bem como aceder ilegalmente informaçóes de outrem, fazer download 
ilegal de músicas/filmes ou plágio. Os direitos e responsabilidades digitais marcham lado a lado com a lei digital. Essa lista de direitos e deveres básicos deve ser estendida, estabelecendo-se, assim, benefícios e obrigaçóes de todos para com todos.

O ideal seria que usuários contribuíssem na construção de uma definição sobre o uso apropriado das TDIC. Na sociedade digital, direitos e responsabilidades devem estar alinhados para que o trabalho de todos seja produtivo. É desconhecido de boa parte dos usuários, por exemplo, que o uso patológico da internet, a adicção, seja um dos problemas advindos da ausência de formação para sua correta utilização. Usuários de todas as idades podem apresentar o distúrbio, que já vem sendo estudado pela medicina e psicologia. Saúde e bem-estar digitais, que compreendem o bemestar físico e psicológico de usuários das TDIC, devem estar no processo de formação e de maneira contínua de modo a assegurar o entendimento acerca da importância do cultivo de bons hábitos que preservem a saúde do indivíduo.

Por último, Ribble alerta para a necessidade de adoção de precauções eletrônicas para garantir a segurança/autoproteção. A segurança digital compreende a utilização de meios de resguardo, como antivírus, backups de dados, senhas seguras e controle rigoroso do equipamento utilizado. Como cidadáos responsáveis, temos o dever de proteger informaçóes de forças exteriores que possam causar danos/prejuízos, por vezes incontornáveis, como a exposição de fotos e dados pessoais.

A cidadania digital é um assunto que deve se tornar cada vez mais relevante na atual sociedade, razão pela qual deve ser um elemento da educação de crianças e jovens. Por isso, o livro de Ribble, que se dirige principalmente a professores da educação primária e secundária nos EUA, evidenciando que também eles deverão ser cidadãos digitais, procura mostrar comportamentos inadequados no uso da TDIC, sugerindo soluçóes e caminhos de abordagem construtiva.

Os elementos apresentados por Ribble poderão constituir importante referencial na perspectiva de orientação para práticas a serem adotadas, ainda que em diferentes realidades, por professores e alunos, que devem, no novo cenário, ser os co-criadores dos alicerces da sociedade digital que se constrói para além das fronteiras de cada país. 


\section{Referências}

ALMEIDA, F. J. SILVA, M. G. M. O currículo como direito e a cultura digital. Revista e-Curriculum, v.12, n.2, 2014. Disponível em: https://revistas.pucsp.br/index.php/ curriculum/article/view/20229 Acesso em: 05 mai. 2018.

BRASIL. Constituição da República Federativa do Brasil. Brasília: Senado, 1988.

BRASIL. Lei 9.934 de 20 de dezembro de 1996. Estabelece as diretrizes e bases da educação nacional. Diário Oficial da União, Brasília, 23 dez. 1996. Disponível em http://www.planalto.gov.br/Ccivil_03/leis/L9394.htm. Acesso: 14 mai 2018.

BRASIL. Marco civil da Internet. 2. ed. Brasília: Ediçóes Câmara, 2015.

UNITED NATIONS. General Assembly. Report of the Special Rapporteur on the promotion and protection of the right to freedom of opinion and expression, Frank La Rue. New York: OHCHR, 2011. Disponível em http:/www2.ohchr.org/english/bodies/ hrcouncil/docs/17session/A.HRC.17.27_en.pdf>. Acesso: 05 mai.2018. 